\title{
ARTIGOS COLABORATIVOS - PROJETO PILOTO EXTRACLASSE
}

PORTO ALEGRE/RS JUNHO/2018

\author{
Ana Luiza Gonçalves Freire －FGVOnline - anafreire11@gmail.com \\ Tipo: Relato de Experiência Inovadora (EI) \\ Categoria: Métodos e Tecnologias \\ Setor Educacional: EDUCAÇÃO SUPERIOR
}

\begin{abstract}
RESUMO
O presente trabalho avalia os resultados do projeto piloto de redação de artigos científicos introduzido em 2017, no curso de Aperfeiçoamento em Gestão do Esporte sob a chancela das instituições FIFA/FGV/CIES. Os principais desafios pedagógicos deste projeto eram amplificar o debate e aumentar a capacidade de resolução de problemas de uma turma de ensino a distância, usando como base a metodológia Problem Based Learning (PBL). Foram redigidos quatro artigos por alunos das turmas FIFA 8 e 9. Aliar estratégias, métodos, proporcionar situações de aprendizagem para 0 desenvolvimento de habilidades em nosso aluno, esse é o grande desafio do Tutor, além de registrar o processo com vistas a colaborar com a pesquisa em educação.
\end{abstract}

Palavras-chave: aprendizagem colaborativa, situação de aprendizagem, PBL. 
Artigo utilizado como recurso pedagógico no curso de Aperfeiçoamento em Gestão do Esporte FIFA 9 - 2017/2018

\section{Artigos colaborativos - projeto piloto extraclasse}

\section{Introdução}

Esse é um projeto piloto que teve início durante a disciplina de Comunicação de Eventos Esportivos, sob a tutoria da professora Ana Freire, em outubro de 2017, no curso de Aperfeiçoamento em Gestão do Esporte, sob a chancela das instituições FIFA/ FGV/CIES.(Fédération Internationale de Football Association - (FIFA); Fundação Getúlio Vargas (FGV); Centro Internacional de Estudos do Esporte - (CIES).)

O curso Aperfeiçoamento em Gestão de Esportes é composto por seis módulos com conteúdos propostos pelo CIES e contextualizados à realidade brasileira por profissionais da FGV.

A metodologia do curso contempla diversas ferramentas da Internet, incluindo uma Comunidade de Prática, Biblioteca Virtual, Sala de discussão (fórum), Agenda de eventos, Perfil do participante, Chats, Área de Networking, Painel de boas práticas mesclando-as com dois encontros presenciais realizados no início e no final do curso. Essa estratégia, além de enriquecer e flexibilizar a grade curricular, permite que os alunos otimizem sua programação de estudo, criando um network com os demais participantes.

Esse projeto piloto foi pensado como uma situação de aprendizagem colaborativa e diferenciada, baseada na metodologia Problem Based Learning - PBL. Ele foi desenvolvido no último módulo da disciplina, sendo que o conteúdo foi fundamentado no material base da disciplina e oferecido como uma atividade optativa para compor a nota final.

A avaliação de cada disciplina se dá a partir das seguintes atividades: atividade individual ( $\mathrm{Al}$ ); atividade em equipe ( $\mathrm{AE}$ ) ou fórum (FO); participação e intervenções significativas $(\mathrm{PI})$ nas reuniões síncronas e assíncronas; apresentação do estudo de caso, a ser realizado presencialmente.

\section{Objetivo:}

O objetivo da escolha desse método de aprendizagem é de otimizar o pequeno espaço 
de tempo destinado a discussão do módulo 4, da disciplina de Comunicação em Eventos Esportivos. Além de ser vantajoso para os alunos, o fato de trabalhar em pequenos grupos em prol de um mesmo objetivo, exercitou a habilidade de resolução de problemas, de forma colaborativa.

\section{Referencial teórico: aprendizagem colaborativa e o PBL}

No processo de construção do artigo, notou-se que os alunos se tornaram comprometidos pelo aprendizado e conseguiram se organizar, colaborativamente.

No hipertexto, produzido pelos alunos, apareceu a multivocalidade, ou seja, vestígios de muitas falas, apropriações de conteúdo, vários olhares e vozes, na abordagem de um mesmo tema, garantindo a oportunidade de que o mesmo pudesse ser acessado de múltiplas maneiras.

As bases do projeto estão no construtivismo de Jean Piaget, pois o processo estimula a atitude de aprender a aprender. E é fortemente embasada no PBL, auxiliando o aluno a ir à busca do conhecimento e criando hábitos de estudo.

A aprendizagem flexível inteligente, característica da quinta geração da $E A D$, foi exercitada aqui. $O$ ambiente virtual conseguiu potencializar 0 processo de aprendizagem, visto que foram utilizadas interfaces de comunicação síncronas e assíncronas.

Informações e conhecimentos foram cocriados (LÉVY, 1999), traduzindo-se em inteligência coletiva, em uma educação online, sendo uma das manifestações ou fenômenos da cibercultura. (SANTOS, 2009).

Constata-se algumas das bases do projeto no construtivismo de Piaget, bem como nas teorias sócio-culturais de Vygotsky, além de ser fortemente embasada no PBL.

Em 1969, na McMaster University - Canadá, o PBL foi introduzido como proposta metodológica. Ele estimula a problematização de questões relevantes e auxilia a desenvolver competências ligadas à postura investigativa do aluno.

O aluno aprende a refletir criticamente sobre os assuntos abordados e se sente estimulado a buscar soluções criativas, de forma colaborativa.

A aplicação dessa metodologia em cursos a distância, requer elaboração de estratégias 
que possibilitem a interação entre todos durante o processo.

\section{Procedimentos metodológicos; apresentação e discussão dos resultados}

\section{O processo - parte 1}

Uma oportunidade foi oferecida aos alunos que quisessem apresentar os seus pontos de vista, as suas pesquisas, as suas experiências profissionais do mundo do esporte, através de um artigo que seria produzido de forma colaborativa,afinal, em EAD "os recursos dos ambientes de aprendizagem virtual, têm a vantagem de propiciar a gestão da informação segundo critérios preestabelecidos de organização, definidos de acordo com as características do ambiente". (ALMEIDA, 2003). Aqueles que aderissem a ideia do artigo estariam liberados da interação no fórum do Módulo 4 que tratava do mesmo assunto.

Dos 49 alunos, 25 aceitaram o desafio e logo começaram a se organizar. Optaram em trabalhar em pequenos grupos para iniciar a produção por temas.

O tema central deveria ser Comunicação, visto que estávamos estudando essa disciplina no curso. Mas também deveriam abordar os outros eixos do curso, ou seja, Marketing, Direito e Gestão Financeira.

Fizemos uso de algumas ferramentas como google docs, e-mail, para a produção dos textos e edição final, e o WhatsApp como suporte de uma comunicação mais ágil entre os envolvidos, pois "as técnicas precisam ser escolhidas de acordo com o que se pretende que os alunos aprendam..." (MORAN et al, 2000)

As equipes foram formadas e todos se utilizaram dos recursos, google docs e WhatsApp, para a elaboração dos textos, que ao final iriam resultar em um.

Experimentamos novas ideias, novo processo e novas ferramentas para pensar temas da disciplina, de forma coletivae todos estavam motivados.

O artigo número 1 foi entregue no prazo a fim de compor a nota de todos os alunos que participaram do processo.

Poderíamos ter finalizado o processo aqui, visto que trabalhamos as principais questões do PBL, fundamentadas por Araújo e Sastre (orgs.), no livro Aprendizagem baseada em problemas no ensino superior, (2009): 
a) as origens: como iniciamos a inovação?; b) natureza das mudanças: como se caracterizou o processo?; c) níveis de mudanças na inovação: o que representa para cada um?; d) a gradação das mudanças estratégicas: em que fase de desenvolvimento nos encontramos?

O processo - parte 2

Após a finalização da experiência produtiva quando da confecção do artigo coletivo com fins avaliativos referente ao módulo 4, na disciplina de Comunicação em Eventos Esportivos, surgiu a vontade de dar prosseguimento ao processo de produção, sendo que o projeto deveria ser repensado, tanto quanto ao processo, quanto a escolha dos alunos que iriam participar, efetivamente.

No processo inicial, tivemos auxílio de dois alunos: $x x x x x$ e xxxxx, que se demonstraram incansáveis quanto a pensar a organização e a viabilização do projeto piloto. A partir daí, conseguimos editar e adequar o primeiro artigo, o que foi produzido pelos 25 alunos, com o intuito de torná-lo publicável, vimos que era possível e trabalhamos no sentido de oferecer um produto de qualidade.

Percebemos a importância de formar um conselho editorial foi formado, como resultado das conversas entre a Tutora e os dois alunos. A partir daí poderíamos pensar as normas de participação e de publicação. Convidamos alguns alunos da turma FIFA 9 para participar, de forma colaborativa e totalmente experimental, da construção de três novos artigos acadêmicos com fins de publicação nesse projeto piloto extraclasse.

Após o aceite em participar do projeto piloto, entendemos que seria muito importante que os alunos trabalhassem em duplas, fazendo com que existisse uma troca de ideias durante o processo da escrita. As duplas foram formadas e o trabalho iniciado.

Pensamos em realizar um artigo para cada disciplina ofertada no curso de Aperfeiçoamento em Gestão de Esporte, somando um total de 5 artigos até o final do curso. Começamos com a proposta de três áreas de conhecimento: Marketing, Direito e Gestão Financeira.

No percurso, entendemos que o projeto poderia ser mais uma vez repensado. Poderíamos aceitar artigos com um só autor e ainda, que o projeto pudesse ser aproveitado também pelos ex-alunos do curso em suas oito edições passadas.

O projeto piloto poderá ser desenvolvido como na produção de um livro e/ou revista 
impressa, com periodicidade anual; e/ou um Site vinculado a FGV para divulgação dos textos, informações, palestras, entrevistas, Podcast, que sejam vinculadas às disciplinas do curso, etc.

Ao final desse primeiro momento do processo, conseguimos apresentar quatro artigos confeccionados por alunos das turmas FIFA 8 e 9 . O projeto impresso, na forma de um boneco de livro, foi apresentado à Coordenação do Curso e foi aprovado, em abril de 2018.

\section{Escolha das ferramentas}

A escolha ocorreu da seguinte forma:

Primeiramente se deu a escolha, via WhatsApp, do(s) tema(s) que os colegas tinham maior afinidade e/ou disposição em realizar pesquisa;

Foi preciso abrir um google docs para cada artigo, tornando possível a edição do texto a várias mãos;

Recomendou-se a utilização de fontes recentes e/ou um estudo de caso que possa ilustrar o assunto;

Sugeriu-se que se fizesse link com a disciplina em questão tal como se deu o artigo de Comunicação;

Foram convidados alunos das turmas FIFA 8 e 9.

\section{O projeto}

1. Os alunos escritores convidados e que aceitaram participar:

Nomes dos alunos Aloisio, Ayres, Braitner, Bruno, Daniel, Henrique, Hiago, João Paulo, Kelly, Renato, Samuel, Victor..

2. Estabelecemos alguns prazos de entrega:

10.12 - Desenvolver manual - prazos e alguns requisitos para edição

11.12 - Apresentar proposta para colegas - por meio de WhatsApp 
12.12 - Último prazo para manifestação sobre participação dos colegas até 14/12

13 a 14.12 - Distribuição dos temas até 16/12

15.12 a 21.01 - Produção dos textos

22.01 - Entrega dos textos - data essa que foi prorrogada em função do recesso e finalização de uma das disciplinas

Dentre as regras para a elaboração do artigo, sugerimos:

1. Abrir o google docs e enviar o convite aos demais colegas;

2. Os grupos serão formados com até três pessoas, onde um dos integrantes será o editor e um revisor, a não ser em artigo no qual seja avaliada a necessidade da entrada de mais um integrante para fins de pesquisa de campo;

3. Fundamentar adequadamente o texto e apresentar as referências bibliográficas ao final;

4. O artigo completo não deve ultrapassar 20 páginas ( $A 4$, com margens de $2,5 \mathrm{~cm}$, em fonte Times New Roman 12 e espaçamento entre linhas de 1,5), já com a bibliografia;

5. Respeitar a data limite de entrega do texto final;

6. Ao participar desse coletivo de autores os alunos concordam que o artigo terá a participação dos autores, dos colegas que farão a edição e adequação do texto para envio às revistas virtuais, impressas ou própria, e da Tutora, coordenadora do projeto piloto.

Ficou estabelecido que após a entrega dos artigos os textos irão passar por uma última revisão que será feita pela Tutora, ajustando assim o artigo às normas de publicação da revista que planejamos editar.

O aluno xxxxx foi editor de dois artigos: um em parceria com a aluna xxxxx intitulado "Desafios da comunicação esportiva: gestão, marketing e departamento jurídico" e outro intitulado "Aspectos sociais das transferências envolvendo atletas de futebol".

Percebemos que a medida que os artigos começaram a ser produzidos e entregues pelos pares, que a classificação dos mesmos era de relevância ao curso em que estão vinculados, merecendo então, uma publicação própria. 
Grandes são os desafios de uma tutoria a distância. Aliar estratégias, métodos, proporcionar novas situações de aprendizagem para o desenvolvimento de habilidades em nosso aluno, faz parte do fazer pedagógico do Tutor, registrar o processo acaba se tornando uma quase que obrigação para aqueles comprometidos com seu ofício e, sobretudo, com a pesquisa em educação a distância.

A PBL possibilitou que os alunos criassem hábitos de estudo e pesquisa, e, além disso, que melhorassem sua performance no curso e na disciplina exercitando a discussão de temas relevantes à sua prática profissional.

Por fim, vimos o quanto importante foi o processo em função da promoção da autonomia de aprendizagem e, sobretudo, do trabalho em equipe.

\section{Referências:}

ALMEIDA, M. E. B. Educação, ambientes virtuais e interatividade. In: SILVA, M. Educação online. São Paulo: Edições Loyola, 2003.

ARAÚJO e SASTRE (orgs.). Aprendizagem baseada em problemas no ensino superior. São Paulo: Summus, 2009.

FONSECA, S. M. e FONSECA; Neto, J. A. M. Metodologias ativas aplicadas à educação a distância: revisão de Literatura. Disponível em: https://seer.ufs.br/index.php/edapeci/article/download/6509/pdf. Acesso em: Maio de 2018.

LÉVY, P. Cibercultura. São Paulo: Editora 34, 1999.

MASETTO, M. T. Mediação pedagógica e o uso da tecnologia. In: MORAN, I. M. Novas tecnologias e mediação pedagógica. São Paulo: Papirus, 2000.

REVISTA IBEROAMERICANA DE EDUCACIÓN. N.ํ51 (2009), pp. 263-266.

SANTOS, E. Educação online para além da EAD: um fenômeno da Cibercultura. Disponível

em: http://www.educacion.udc.es/grupos/gipdae/documentos/congreso/xcongreso/pdfs/t12/t1 2c427.pdf. Acesso em maio/2018.

VYGOTSKY, L. S. A formação social da mente. 6. ed. São Paulo: Martins Fontes, 1998. 
